\title{
Porcine enteric coronavirus infections in wild boar in Poland - a pilot study
}

\author{
Marta Antas $^{1 \otimes}$, Monika Olech ${ }^{2}$, Anna Szczotka-Bochniarz ${ }^{1}$ \\ ${ }^{1}$ Department of Swine Diseases, ${ }^{2}$ Department of Biochemistry, \\ National Veterinary Research Institute, 24-100 Puławy, Poland \\ marta.antas@piwet.pulawy.pl
}

Received: February 16, $2021 \quad$ Accepted: July 1, 2021

\begin{abstract}
Introduction: Porcine epidemic diarrhoea virus (PEDV) of the Coronaviridae family causes significant economic losses in the pig industry worldwide. Wild boars contribute to the transmission of different viral, bacterial and parasitic infections to livestock animals and humans. However, their role in the maintenance and transmission of PEDV has not been established. Material and Methods: In this study, blood and faecal samples from 157 wild boars were collected from 14 provinces of Poland during the 2017-2018 hunting season. RNA was extracted from the faecal homogenate supernatant and subjected to quantitative RT-PCR (RT-qPCR), while clotted blood samples were used for detection of antibodies against PEDV by ELISA. Results: Five blood samples (3.2\%) were seropositive in ELISA, while none of the faecal samples were found positive using RT-qPCR assays. Conclusion: The results of this analysis indicate the need for additional studies incorporating a larger number of samples and preferably comparing different serological methods, to confirm whether wild boars in Poland act as PEDV reservoirs.
\end{abstract}

Keywords: porcine epidemic diarrhoea virus, wild boar, ELISA, RT-qPCR.

\section{Introduction}

Porcine epidemic diarrhoea virus (PEDV) is an enveloped, single-stranded RNA virus belonging to the Coronaviridae family in the Alphacoronavirus genus. The PEDV genome is approximately 28 kilobase pairs long and consists of seven open reading frames (ORFs) that encode four major structural proteins, namely spike $(\mathrm{S})$, envelope $(\mathrm{E})$, membrane $(\mathrm{M})$ and nucleocapsid $(\mathrm{N})$, and three non-structural proteins (1a, 1ab and ORF3) (6). In general, genetic diversity has been described as being higher among the PEDV $\mathrm{S}$ and E genes than the $\mathrm{M}$ and $\mathrm{N}$ genes. The virus is assumed to undergo a slow evolutionary process generating mutations or recombination events necessary for adaptation. The stability and high-fidelity replication of its large genome can be attributed to the $3^{\prime}-$ to- $5^{\prime}$ proofreading exoribonuclease activity within non-structural protein nsp14 (30). Although only one serotype of PEDV has been reported, phylogenetic studies of the $\mathrm{S}$ gene suggested that PEDV can be divided into two groups: the low-pathogenic genogroup 1 (G1a and recombinant G1b) and highly pathogenic genogroup 2 (local epidemic G2a and global epidemic or pandemic G2b) (14-16, 37).
This virus is one of the major pathogens causing a devastating disease in the swine industry which is characterised by vomiting and acute watery diarrhoea leading to dehydration and high mortality, especially in young piglets $(13,23-24,26)$. The disease is clinically similar to other forms of porcine gastroenteritis caused by closely related coronaviruses, transmissible gastroenteritis virus (TGEV), porcine deltacoronavirus (PDCoV), rotaviruses, bacteria (Clostridium spp., E. coli, Salmonella spp., Brachyspira spp., and Lawsonia intracellularis) and parasites (Isospora suis, Cryptosporidium spp., and nematodes) (24, 27). Therefore, a diagnosis of PEDV infection cannot be made based only on the clinical signs and lesions observed in the gastrointestinal tract during necropsy. Many diagnostic tests have been developed and are commonly used to detect PEDV genetic material and its proteins, including virus isolation, immunofluorescence (IF), immunohistochemistry (IHC) and polymerase chain reaction (PCR) $(20,32,38)$. Additionally, several serological methods such as enzyme-linked immunosorbent assay (ELISA) have been designed and proven to detect antibodies against PEDV. While earlier indirect ELISAs were based on whole virus preparation, more recently developed tests are based on the spike or the 
nucleocapsid proteins $(8,17,25)$. Molecular assays such as real-time quantitative reverse transcriptase PCR (RT-qPCR) have become the methods routinely used for the diagnosis of PEDV infection, providing sensitive, specific and rapid detection of viral RNA in clinical samples. Notwithstanding the popularity of chain reaction methods, the measurement of antibodies against PEDV by ELISA can still be useful to detect positive animals beyond the excretion period for different purposes, such as to know the possible presence, persistence and spread of the virus within the farm, to screen the source animals' status, to check the immune status of gilts and sows before farrowing, and to conduct immunological and epidemiological studies on PEDV.

In the last decade, many porcine epidemic diarrhoea (PED) outbreaks have been reported by several countries. The virus was first recognised in the UK in 1971 and later spread through most European countries (France, Portugal, Germany, the Netherlands, Austria, Italy, Slovenia, and Ukraine), Asia, and North America (USA, Mexico and Canada) (3, 5, 12, 23, 33-35). Because PED is not a notifiable disease in the EU nor among the OIE listed diseases, most countries have not implemented active monitoring for this particular disease, so information about its prevalence is lacking or limited. In Poland, the clinical symptoms of PED have been observed in pigs but no large-scale studies have been performed.

It is known that the wild boar (Sus scrofa L.) is a reservoir for a variety of significant pathogens responsible for diseases in livestock animals and in particular in swine $(22,29,36)$. Among other disease agents, classical swine fever virus (CSFV), pseudorabies virus (PRV), African swine fever virus (ASFV), porcine circovirus type 2 (PCV2), porcine reproductive and respiratory syndrome virus (PRRSV) and porcine parvovirus (PPV) are confirmed to circulate in the wild boar population (4). However, the role of wild boars in the maintenance and transmission of PEDV is not well known. Studies conducted by Lee et al. (15) confirmed the circulation of PEDV in the wild boar population on the Korean peninsula. However, to the best of our knowledge, there is no other published information regarding PEDV occurrence in wild boars. Therefore, the goal of the current study was the detection of antibodies and genetic material of PEDV in samples collected from representatives of the species in Poland.

\section{Material and Methods}

The study was performed using samples procured at random from 157 wild boars originating from 14 provinces of Poland covering most of the area of the country. The experimental material was amassed during the 2017-2018 hunting season (Fig. 1). Blood samples were taken directly from the heart, mainly as blood clots, and faecal samples were collected from the rectum of corresponding animals. All materials were stored at $-80^{\circ} \mathrm{C}$ prior to testing. No ethical authority approval was required as the blood and faeces were collected post mortem by licensed hunters.

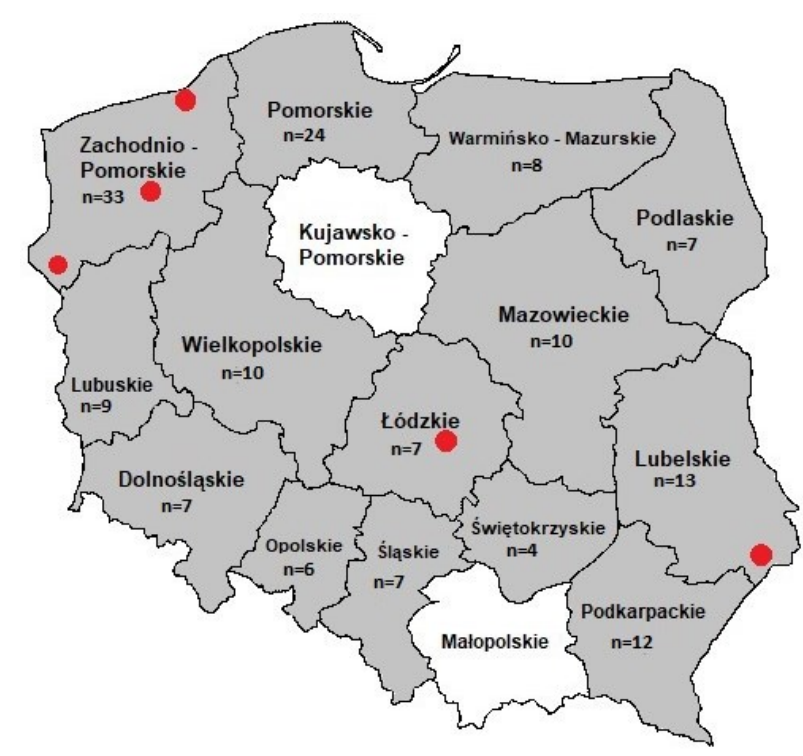

Fig. 1. Geographic distribution of samples collected from wild boars in Poland. Areas in grey correspond to voivodships from which samples were collected. The red dots indicate the areas of origin of wild boar samples found positive in ELISA assays; $n$ - the number of samples collected in particular areas

Faecal samples were diluted tenfold in phosphate buffered saline (PBS) containing antibiotics (10 units $/ \mathrm{mL}$ of penicillin, $100 \mu \mathrm{g} / \mathrm{mL}$ of streptomycin, and $0.25 \mu \mathrm{g} / \mathrm{mL}$ of amphotericin B) (Gibco, Grand Island, NY, USA) and centrifuged at $3,000 \mathrm{rpm}$ for $20 \mathrm{~min}$ at $4^{\circ} \mathrm{C}$. The supernatant was collected and total RNA was extracted using a QIAmp Viral RNA Mini Kit (Qiagen, Hilden, Germany) and tested for the presence of PEDV by RT-qPCR using a VetMAX PEDV/TGEV/SDCoV Kit (Thermo Fisher Scientific, Waltham, MA, USA) according to the manufacturer's recommendations. The thermal cycling conditions were as follows: $10 \mathrm{~min}$ at $48^{\circ} \mathrm{C}$ for reverse transcription, $10 \mathrm{~min}$ at $94^{\circ} \mathrm{C}$ for initial denaturation, and 40 cycles of $15 \mathrm{~s}$ at $95^{\circ} \mathrm{C}$ and $45 \mathrm{~s}$ at $60^{\circ} \mathrm{C}$ for denaturation, annealing, and extension. A $20 \mu \mathrm{L}$ volume of the reaction mixture contained $5 \mu \mathrm{L}$ of TaqMan Fast Virus 1-step Master Mix (Thermo Fisher Scientific), $1 \mu \mathrm{L}$ of VetMAX PEDV/TGEV/SDCoV Primer Probe Mix, $6 \mu \mathrm{L}$ of Nuclease-Free Water (Thermo Fisher Scientific), and $8 \mu \mathrm{L}$ of RNA of tested samples. For each separate RT-qPCR run, two positive controls (one for the RT-qPCR components and another for the RNA purification process) and one negative control (nuclease-free water, Amresco, Solon, OH, USA) were included. The reactions RT-qPCR were run on an Mx3005P qPCR System (Agilent Technologies, Santa Clara, CA, USA) according to the manufacturer's instructions. A positive control was used to set the cycle threshold $(\mathrm{Ct})$ for evaluating test results.

A recombinant $\mathrm{N}$ protein-based commercial ELISA (ID Screen PEDV Indirect, IDvet, Grabels, France) was used for detection of anti-PEDV antibodies 
in blood samples. The assay was performed and interpreted according to the manufacturer's recommendations. Briefly, $10 \mu \mathrm{L}$ of plasma was added to each well containing $90 \mu \mathrm{L}$ of dilution buffer. After incubation at $21^{\circ} \mathrm{C}$ for $45 \mathrm{~min}$, the wells were washed three times with the Wash Solution Buffer. Thereafter, $100 \mu \mathrm{L}$ of $1 \times$ conjugate was added and the mixture was incubated for $30 \mathrm{~min}$ at $21^{\circ} \mathrm{C}$. After washing, $100 \mu \mathrm{L}$ of substrate solution was added and after incubation for $15 \mathrm{~min}$ at $21^{\circ} \mathrm{C}, 100 \mu \mathrm{L}$ of a stop solution was used to interrupt the colour reaction. The plates were read at $450 \mathrm{~nm}$ using a ELx800 plate reader (BioTek Instruments, Winooski, VT, USA). The results were expressed as a percentage of the sample-to-positive $(\mathrm{S} / \mathrm{P})$ ratio and the samples which showed an $\mathrm{S} / \mathrm{P}$ higher than $60 \%$ were considered positive.

\section{Results}

Out of 157 tested samples, five (3.2\%) samples, which originated from three voivodships (Fig. 1), were positive in the $\mathrm{N}$ protein-based commercial test, while 152 (96.8\%) samples were negative. The S/P \% values obtained from positive samples exceeded the threshold for positivity ( $\geq 60 \%$ ) and ranged from $73 \%$ to $197 \%$ (Fig. 2).

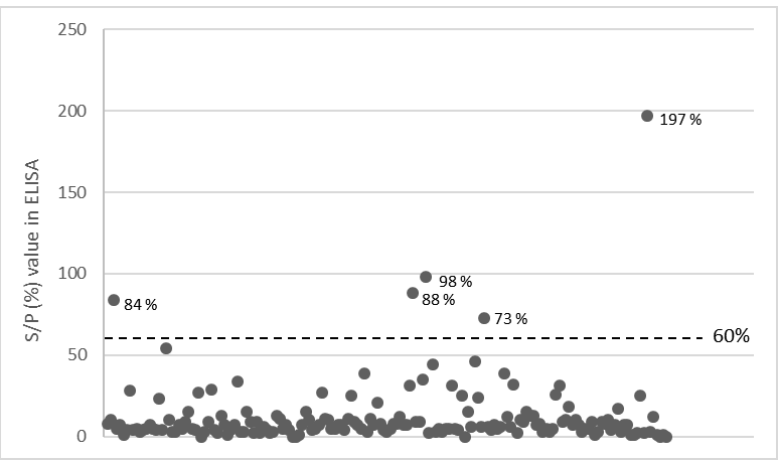

Fig. 2. Distribution of the $\mathrm{S} / \mathrm{P}(\%)$ values of samples tested in this study. The samples which yielded $\mathrm{S} / \mathrm{P}$ ratios higher than $60 \%$ (the cutoff shown as the dotted line) were considered PEDV-positive, and samples with lower ratios were considered negative

A multiplex RT-qPCR was carried out to detect the genome of PEDV and possible coinfection(s) with TGEV and PDCoV; however, the presence of the genetic material of these viruses was not detected in samples tested in this study.

\section{Discussion}

There has been a worldwide increase in the number and geographical spread of wild boar populations (2). Changes of human habitation to suburban areas, increased use of land for agricultural purposes, increased hunting of wild boars and consumption of wild boar meat in some regions have increased the opportunity for exposure of domestic animals and humans to wild boars and created an ideal environment for the transmission of pathogens from the latter to the former (10). Previous epidemiological studies indicated that wild boars are a potential reservoir for infectious diseases of livestock and humans (2). Therefore, epidemiological studies of different pathological agents of economic and public health importance are necessary in wild boars. For this reason, the objective of the present study was to determine the prevalence of PEDV in wild boars from Poland. A total of 157 blood and faecal samples from wild boars were analysed using RT-qPCR and ELISA tests for detection of viral genetic material and PEDVspecific antibodies, respectively. Our results indicated that five samples (3.2\%) were seropositive, however, the presence of genetic material of this pathogen was not detected. Similar results were obtained in the USA in study by Ghimire et al. (9), where faecal samples originating from 44 wild boars were tested by conventional RT-PCR and RT-qPCR assays and found negative. On the other hand, the study conducted by Lee et al. (15) indicated the circulation of PEDV in the wild boar population in South Korea: the analysis of 287 samples tested by RT-PCR revealed a PEDV infection rate of $9.75 \%(28 / 287)$. The PEDV sequences obtained from wild boar isolates were closely related to sequences of the Chinese PEDV strain, showing 97.7-100.0\% homology. However, the molecular and phylogenetic analyses were limited to partial sequences encoding the spike protein.

Taking into account the high sensitivity and specificity of the molecular methods, they can be used in the early stages of PEDV infection; however, as the disease continues, the number of virus particles in the clinical material decreases as a result of the immune system mechanisms, and then these tests become less useful. More specifically, PEDV faecal shedding is the highest a few days post infection and the viral load tends to decrease after one week; however, intermittent shedding can be observed until 60 days post infection (1). Therefore, in a study using faecal samples, the likelihood of detecting the virus is higher before the infection has encountered the full host response. For this reason, our results may indicate that the wild boars tested in this study did not have active PEDV infection. However, the detection of antibodies against PEDV in some samples suggests that these animals could have had earlier contact with the virus which resulted in the production of antibodies that are known to persist for more than a year $(8,27)$.

Currently, several enzyme-linked immunosorbent assays (ELISA) have been developed to detect antibodies against $\operatorname{PEDV}(7,13,19,28)$. However, most of them are in-house assays and information regarding their sensitivity and specificity is scarce. The contrasting requirements for high sensitivity and high specificity have always been a challenge for ELISA developers. It is known that a decrease in diagnostic specificity will result in an increased number of false positives, while 
increasing the test specificity will result in decreased sensitivity and lead to fewer true- and false-positive results. In this study we used a commercially available ELISA kit which had sensitivity and specificity of $73.7 \%$ and $98.4 \%$, respectively (8). This kit is based on the nucleoprotein ( $\mathrm{N}$ protein) of PEDV, which is massively produced throughout infection and is able to elicit a strong immune response $(13,31)$. Moreover, this protein is highly conserved among PEDV strains (96-99.7\% amino acid identity), which suggests that ELISAs based on the $\mathrm{N}$ protein could be more sensitive for detection of antibodies against heterologous PEDV strains than ELISAs based on the more variable spike protein (18). The amino acid similarity of the PEDV N protein to that of other porcine coronaviruses is lower than $35 \%$; however, it contains the epitopes which are highly conserved among the Coronaviridae family, and crossepitopes with certain TGEV $(11,19)$ and PDCoV strains have been reported (21). Therefore, it cannot be ruled out that among the results of this small-scale study there may be some false positives due to cross-reactions. The lack of well-established tests for serological diagnosis of PEDV infection definitely hampers the monitoring of carriage of the virus. Further studies resourced with larger sample sizes and using different serological and molecular methods are recommended to confirm whether wild boars in Poland act as a PEDV reservoir.

Conflict of Interests Statement: The authors declare that there is no conflict of interests regarding the publication of this article.

Financial Disclosure Statement: The scientific activity of Marta Antas M.Sc. was supported by grant S/384 to sustain and foster research potential: "Occurrence of porcine epidemic diarrhoea (PED) in Poland and development of molecular biology methods for identification and differentiation of PEDV, transmissible gastroenteritis virus (TGEV), and porcine deltacoronavirus (PDCoV) in samples of slurry from pig farms in Poland".

Animal Rights Statement: This study did not require official or institutional ethical approval. No animals were hunted for the purpose of this study. Certified hunters shot the wild boars during hunting seasons, and the material was collected post mortem. The data were handled confidentially.

\section{References}

1. Bertasio C., Giacomini E., Lazzaro M., Perulli S., Papetti A., Lavazza A., Lelli D., Alborali G., Boniotti M.B.: Porcine Epidemic Diarrhea Virus Shedding and Antibody Response in Swine Farms. A Longitudinal Study. Front Microbiol 2016, 7, 2009, doi: 10.3389/fmicb.2016.02009.

2. Brown V.R., Bowen R.A., Bosco-Lauth A.M.: Zoonotic pathogens from feral swine that pose a significant threat to public health. Transbound Emerg Dis 2018, 65, 649-659, doi: 10.1111/tbed.12820.
3. Dastjerdi A., Carr J., Ellis R.J., Steinbach F., Williamson S.: Porcine Epidemic Diarrhea Virus among Farmed Pigs, Ukraine. Emerg Infect Dis 2015, 21, 2235-2237, doi: 10.3201/eid2112.150272.

4. Dong D.U., Kwon T., Je S.H., Yoo S.J., Seo S.W., Sunwoo S.Y., Lyoo Y.S.: Wild boars harbouring porcine epidemic diarrhea virus (PEDV) may play an important role as a PEDV reservoir. Vet Microbiol 2016, 192, 90-94, doi: 10.1016/j.vetmic.2016.07.003.

5. Dortmans J.C.F.M., Li W., van der Wolf P.J., Buter G.J., Franssen P.J.M., van Schaik G., Houben M., Bosch B.J.: Porcine epidemic diarrhea virus (PEDV) introduction into a naive Dutch pig population in 2014. Vet Microbiol 2018, 221, 13-18, doi: 10.1016/j.vetmic. 2018.05.014.

6. Duarte M., Tobler K., Bridgen A., Rasschaert D., Ackermann M., Laude H.: Sequence Analysis of the Porcine Epidemic Diarrhea Virus Genome between the Nucleocapsid and Spike Protein Genes Reveals a Polymorphic ORF. Virology 1994, 198, 466-476, doi: 10.1006/viro.1994.1058.

7. Fan J.H., Zuo Y.-Z., Shen X.-Q., Gu W.-Y., Di J.-M.: Development of an enzyme-linked immunosorbent assay for the monitoring and surveillance of antibodies to porcine epidemic diarrhea virus based on a recombinant membrane protein. J Virol Methods 2015, 225, 90-94, doi: 10.1016/j.jviromet.2015.07.021.

8. Gerber P.F., Lelli D., Zhang J., Strandbygaard B., Moreno A., Lavazza A., Perulli S., Bøtner A., Comtet L., Roche M., Pourquier P., Wang C., Opriessnig T.: Diagnostic evaluation of assays for detection of antibodies against porcine epidemic diarrhea virus (PEDV) in pigs exposed to different PEDV strains. Prev Vet Med 2016, 135, 87-94, doi: 10.1016/j.prevetmed.2016.11.005.

9. Ghimire S.: Master thesis: Screening for enteric coronaviruses in fecal samples of feral pigs of California, USA. The Ohio State University, Wooster, OH, 2017, pp. 1-74.

10. Gibbs E.P.J.: The public health risks associated with wild and feral swine. Rev Sci Tech Off Int Epiz 1997, 16, 594-598, doi: 10.20506/rst.16.2.1052.

11. Gimenez-Lirola L.G., Zhang J., Carrillo-Avila J.A., Chen Q., Magtoto R., Poonsuk K., Baum D.H., Piñeyro P., Zimmerman J.: Reactivity of Porcine Epidemic Diarrhea Virus Structural Proteins to Antibodies against Porcine Enteric Coronaviruses: Diagnostic Implications. J Clin Microbiol 2017, 55, 1426-1436, doi: 10.1128/JCM.02507-16.

12. Grasland B., Bigault L., Bernard C., Quenault H., Toulouse O., Fablet Ch., Rose N., Touzain F., Blanchard Y.: Complete Genome Sequence of a Porcine Epidemic Diarrhea S Gene Indel Strain Isolated in France in December 2014. Genome Announc 2015, 3, e00535-15, doi: 10.1128/genomeA.00535-15.

13. Hou X.-L., Yu L.-Y., Liu J., Wang G.-H.: Surface-displayed porcine epidemic diarrhea viral (PEDV) antigens on lactic acid bacteria. Vaccine 2007, 26, 24-31, doi: 10.1016/j.vaccine. 2007.10.065.

14. Huang Y-W., Dickerman A.W., Piñeyro P., Li L., Fang L., Kiehne R., Opriessnig T., Meng X.-J.: Origin, evolution, and genotyping of emergent porcine epidemic diarrhea virus strains in the United States. mBio 2013, 4, e00737-13, doi: 10.1128/mBio.00737-13.

15. Lee Ch.: Porcine epidemic diarrhea virus: an emerging and re-emerging epizootic swine virus. Virol J 2015, 12, 193, doi: 10.1186/s12985-015-0421-2.

16. Lee S., Lee Ch.: Outbreak-related porcine epidemic diarrhea virus strains similar to US strains, South Korea, 2013. Emerg Infect Dis 2014, 20, 1223-1226, doi: 10.3201/eid2007.140294.

17. Li Y., Zheng F., Fan B., Muhammad H.M., Zou Y., Jiang P.: Development of an indirect ELISA based on a truncated $S$ protein of the porcine epidemic diarrhea virus. Can J Microbiol 2015, 61, 811-817, doi: 10.1139/cjm-2015-0213.

18. Lin Ch-M., Annamalai T., Liu X., Gao X., Lu Z., El-Tholoth M., Hu H., Saif J.L., Wang Q.: Experimental infection of a US spikeinsertion deletion porcine epidemic diarrhea virus in conventional nursing piglets and cross-protection to the original US PEDV infection. Vet Res 2015, 46, 134, doi: 10.1186/s13567-015-0278-9.

19. Lin H., Li B., Liu M., Zhou H., He K., Fan H.: Nonstructural protein 6 of porcine epidemic diarrhea virus induces autophagy to 
promote viral replication via the $\mathrm{PI} 3 \mathrm{~K} / \mathrm{Akt} / \mathrm{mTOR}$ axis. Vet Microbiol 2020, 244, 108684, doi: 10.1016/j.vetmic. 2020.108684.

20. Lyoo K.-S., Yeom M., Kim J., Kim D., Ha G., Na W., Le VP., Song D.: Development of rapid immunochromatographic strip test for the detection of porcine epidemic diarrhoea virus. Vet Rec 2017, 181, 596, doi: 10.1136/vr.103959.

21. Ma L., Zeng F., Huang B., Zhu Y., Wu M., Xu F., Xiao L., Huang R., Ma J., Cong F., Guo P.: Point-of-care diagnostic assay for rapid detection of porcine deltacoronavirus using the recombinase polymerase amplification method. Transbound Emerg Dis 2019, 66, 1324-1331, doi: 10.1111/tbed.13155.

22. Meng X.J., Lindsay D.S., Sriranganathan N.: Wild boars as sources for infectious diseases in livestock and humans. Phil Trans R Soc B 2009, 364, 2697-2707, doi: 10.1098/rstb.2009.0086.

23. Mesquita J.R., Hakze-van der Honing R., Almeida A., Lourenço M., van der Poel W.H.M., Nascimento M.S.J.: Outbreak of Porcine Epidemic Diarrhea Virus in Portugal, 2015. Transbound Emerg Dis 2015, 62, 586-588, doi: 10.1111/tbed.12409.

24. Myint O., Yoshida A., Sekiguchi S., Van Diep N., Fuke N., Izzati U.Z., Hirai T., Yamaguchi R.: Development of indirect enzyme-linked immunosorbent assay for detection of porcine epidemic diarrhea virus specific antibodies ( $\mathrm{IgG})$ in serum of naturally infected pigs. BMC Vet Res 2019, 15, 409, doi: 10.1186/s12917-019-2123-2.

25. Okda F., Liu X., Singrey A., Clement T., Nelson J., ChristopherHennings J., Nelson E.A., Lawson S.: Development of an indirect ELISA, blocking ELISA, fluorescent microsphere immunoassay and fluorescent focus neutralization assay for serologic evaluation of exposure to North American strains of Porcine Epidemic Diarrhea Virus. BMC Vet Res, 2015, 11, 180, doi: 10.1186/s12917-015-0500-z.

26. Pensaert M.B., Martelli P.: Porcine epidemic diarrhea: a retrospect from Europe and matters of debate. Virus Res 2016, 226, 1-6, doi: 10.1016/j.virusres.2016.05.030.

27. Pospischil A., Stuedli A., Kiupel M.: Diagnostic Notes: Update on porcine epidemic diarrhea. J Swine Heal Prod 2002, 10, 81-85.

28. Ren X., Suo S., Jang Y.S.: Development of a porcine epidemic diarrhea virus $\mathrm{M}$ protein-based ELISA for virus detection. Biotechnol Lett 2011, 33, 215-220, doi: 10.1007/s10529-0100420-8.
29. Ruiz-Fons F., Segalés J., Gortázar Ch.: A review of viral diseases of the European wild boar: Effects of population dynamics and reservoir rôle. Vet J 2008, 176, 158-169.

30. Smith E.C., Denison M.R.: Implications of altered replication fidelity on the evolution and pathogenesis of coronaviruses. Curr Opin Virol 2012, 2, 519-524, doi: 10.1016/j.coviro.2012.07.005.

31. Song D., Moon H., Kang B.: Porcine epidemic diarrhea: a review of current epidemiology and available vaccines. Clin Exp Vaccine Res 2015, 4, 166-176, doi: 10.7774/cevr.2015.4.2.166.

32. Song Y., Singh P., Nelson E., Ramamoorthy S.: A Computationally Designed Serological Assay for Porcine Epidemic Diarrhea Virus. J Clin Microbiol 2016, 54, 2039-2046, doi: 10.1128/JCM.00460-16.

33. Stadler J., Susanne Z., Fux R., Hanke D., Pohlmann A., Blome S., Weissenböck H., Weissenbacher-Lang C., Ritzmann M., Ladinig A.: Emergence of porcine epidemic diarrhea virus in southern Germany. BMC Vet Res 2015, 11, 142, doi: 10.1186/s12917-0150454-1.

34. Steinrigl A., Revilla Fernández S., Stoiber F., Pikalo J., Sattler T., Schmoll F.: First detection, clinical presentation and phylogenetic characterization of Porcine epidemic diarrhea virus in Austria. BMC Vet Res 2015, 11, 310, doi: 10.1186/s12917-015-0624-1.

35. Toplak I., Ipavec M., Kuhar U., Kušar D., Papić B., Koren S., Toplak N.: Complete Genome Sequence of the Porcine Epidemic Diarrhea Virus Strain SLO/JH-11/2015. Genome Announc 2016, 4, e 01725-15, doi: 10.1128/genomeA.01725-15.

36. Wiethoelter A.K., Beltrán-Alcrudo D., Kock R., Mor S.M.: Global trends in infectious diseases at the wildlife-livestock interface. PNAS 2015, 112, 9662-9667, doi: 10.1073/pnas. 1422741112

37. Won H., Lee D.-U., Jang G., Noh Y.-H., Lee S.-Ch., Choi H.-W., Yoon I.-J., Yoo H.S., Lee Ch.: Generation and protective efficacy of a cold-adapted attenuated genotype $2 \mathrm{~b}$ porcine epidemic diarrhea virus. J Vet Sci 2019, 20, e32, doi: 10.4142/ jvs.2019.20.e32.

38. World Organisation for Animal Health (OIE): OIE Technical Factsheet: Infection with porcine epidemic diarrhoea virus. Aetiology Epidemiology Diagnosis Prevention and Control References. World Organisation for Animal Health, Paris, 2014. https://doc.oie.int/seam/resource/directMedia/11TrFXA0_YFRK PAjhnFSOU50tNjA6zFT? binaryFileId $=967 \&$ cid $=75970$. 